\title{
Prenatal detection of short arm deletion and isochromosome 18 formation investigated by molecular techniques
}

Cytogenetics

Laboratory, Box 3607,

Duke University

Medical Center,

Durham, NC 27710,

USA

M B Qumsiyeh

Department of

Obstetrics and

Gynecology, UT

College of Medicine,

910 Blackford Street,

Chattanooga, TN

37403, USA

A Tomasi

M Taslimi

Correspondence to:

Dr Qumsiyeh.

Received 1 March 1995

Revised version accepted for publication 14 July 1995

\begin{abstract}
A patient was referred for amniocentesis because of advanced maternal age and polyhydramnios. The fetal karyotype was a mosaic 46,XX,del(18)(p11.1)/46,XX, -18 , $+\mathbf{i}(18 q)$ de novo. The deletion appeared to encompass the whole short arm as evidenced by $G$ banding and in situ hybridisation. However, telomere sequences were found on both ends of the deleted chromosome as well as the isochromosome. The normal 18 and the isochromosome showed more alphoid sequences than the del(18). Subsequent passages of the cell lines showed an increase in the frequency of the isochromosome from $20 \%$ to about $30 \%$. Possible mechanisms are discussed.
\end{abstract}

( $\mathcal{F}$ Med Genet 1995;32:991-993)

Fissions, isochromosomes, and whole arm translocations with breakpoints at or very near the centromere are uncommon in human clinical cytogenetics. The few cases reported appear limited to selected chromosomes. Examples include fissions in chromosome $4,{ }^{1}$ isochromosomes 12,18 , and $\mathrm{X},{ }^{2-10}$ and whole arm translocations involving 18 and $21 .{ }^{11}$ Studies on isochromosome $\mathrm{X}$ suggest a deletion of the short arm as a possible initiating mechanism with many cases of dicentric X chromosomes. ${ }^{46}$ Schinzel ${ }^{12}$ discussed the difficulty in deciding whether fissions give rise to deletions or if the opposite is true. Recently, Cantú et al ${ }^{13}$ reported a whole arm translocation involving chromosomes 18 and 20 in which a break in the alphoid/centromeric sequences may have been involved. Fluorescence in situ hybridisation (FISH) investigation of a whole arm translocation 1;7 in myelodysplasia showed the presence of alphoid sequences from both chromosomes 1 and 7 in the derivative chromosome. ${ }^{14} \mathrm{~A}$ similar case was investigated by Tümer $e t a l^{15}$ who concluded that alpha satellite DNA was involved in the translocation 18;20 in their case. These examples suggest that DNA sequences at or near the centromeres and telomeres may play a key role in formation of isochromosomes and whole arm translocations. We report a prenatally diagnosed case where such events may have played a role in the formation of a mosaic deletion and isochromosome for chromosome 18.

\section{Case report}

The patient was referred for cytogenetic testing because of advanced maternal age ( 42 years) and polyhydramnios. This was the fifth pregnancy in this patient. The first pregnancy ended in a stillborn male with breech presentation and placenta praevia (no other information was available). Three other pregnancies were apparently without complications and no phenotypic abnormalities were reported in these children (ages 6,15 , and 22 years). Polyhydramnios was observed at a gestational age of 25 weeks and an amniocentesis was performed (the patient had refused earlier prenatal diagnosis). Amniotic fluid alphafetoprotein was $6 \cdot 2$ and a screen for acetylcholine esterase was negative. Cytogenetic evaluation from amniotic fluid cells showed 16 cells with a 46,XY, $\operatorname{del}(18)$ (pcen or p11.1) and four cells with 46 , $\mathrm{XY},-18,+\mathrm{i}(18 \mathrm{q})$. Normal cells were not seen in any of the three coverslip cultures and two flask cultures examined. The patient was counselled that the child at birth could have a phenotype consistent with both non-mosaic deletion 18p and mosaic trisomy 18q. Parental karyotypes were normal. The patient elected to have a therapeutic abortion which was performed at another centre. The fetus was not available for our examination. However, photographs (fig 1) obtained after delivery were sent to us and they showed the following phenotypic abnormalities: brachycephaly, low hair line, prominent occiput, hypertelorism, low nasal bridge, broad nose, full lips with down turning corners, micrognathia, slightly low set ears, small pelvis, short fingers, broad hand, and mild club feet.

\section{Methods}

Fluorescence in situ hybridisation was performed using published methods ${ }^{1617}$ with reagents and probes from Oncor, Inc (Gaithersburg, MD). The probes used were an oligonucleotide repeat representing human telomeres and a centromeric probe for chromosome 18 (D18Z1). Biotin labelled probes were hybridised and detected according to the protocol recommended by the supplier (Oncor, Inc). Chromosome preparations were observed under a Zeiss Fluorescence Axiophot microscope with HBO $50 \mathrm{~W}$ DC mercury lamp and filter combinations of BP 450-490, FT 50, and LP 52. Photographs were taken on ASA 400 Kodak gold film. 


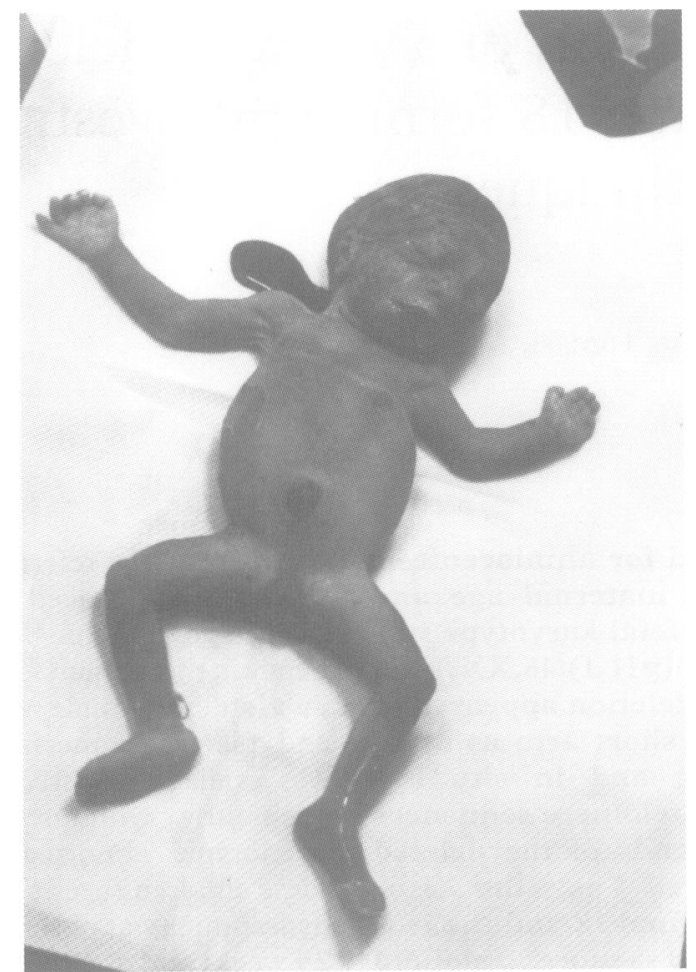

Figure 1 Proband after delivery.

Results and discussion

Initial amniotic fluid cultures showed the presence of a mosaic $46, \mathrm{XX}, \operatorname{del}(18)(\mathrm{p} 11.1) / 46, \mathrm{XX}$, $-18,+i(18 q)$. In addition to the 20 cells initially examined from three coverslips and two flasks, 50 other cells were evaluated from subsequent harvest of three flasks each. Each showed the presence of the mosaic condition with isochromosomes found in 12, 15, and $20 \%$ of the cells examined from these three flasks. The culture with the $20 \%$ mosaicism was subcultured and then harvested two weeks after the first harvest. Results from this harvest showed 14 of 47 cells examined with the isochromosome, a frequency of about $30 \%$. The increase in the frequency of the isochromosome could indicate that this form of the aberration is more stable than the deletion or is selected for in culture. Thus, we speculated initially that the deletion was terminal with a loss of the telomere sequences. We performed in situ hybridisation with both telomere and centromere probes in these cells and the results did not agree with this simple explanation.

In situ hybridisation with the $\mathrm{D} 18 \mathrm{Z} 1$ probe showed weaker hybridisation on the centromeric region of the deleted 18 than on the normal homologous chromosome 18 (fig 2). The isochromosome showed more centromeric hybridisation (fig 2) and C banding (data not shown) than the deleted chromosome 18. The formation of the isochromosome was not accompanied by a retention of the telomere interstitially; none of the 15 cells examined showed a fluorescent signal at the centre of the isochromosome (fig 2). Hybridisation with the telomeric probe showed the deleted chromosome 18 to possess telomeric sequences at both ends of this apparent telocentric chromosome (fig 2). Studies of the hybridisation of

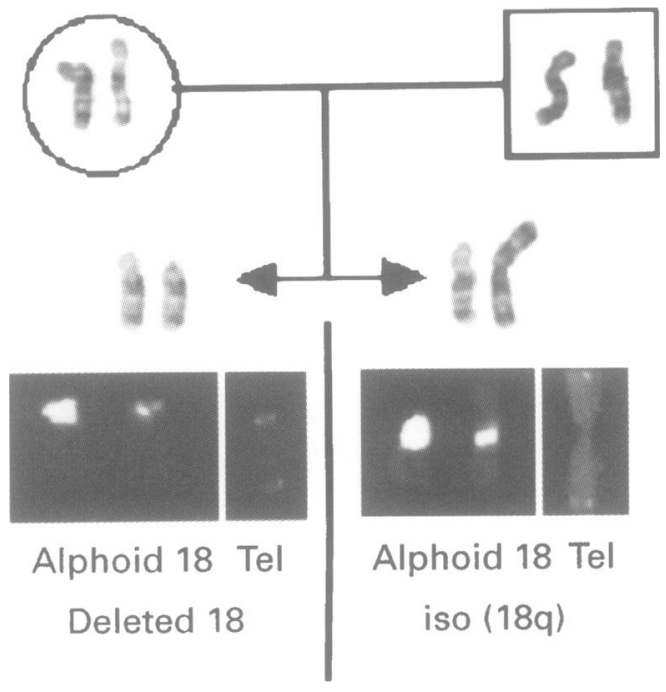

Figure $2 G$ banding and FISH studies on the parents and the fetus showing del(18p) and formation of isochromosome 18. In situ hybridisation with probe D18Z1 (centromere 18) shows reduced fluorescence on the deleted chromosomes. In situ hybridisation with telomere probe shows the presence of telomeric signal on the del(18p) chromosome.

alphoid sequences and of $\mathrm{C}$ band polymorphisms failed to show the parental origin of the rearranged 18. The parents refused to supply blood for additional molecular studies.

Vorsanova $e t$ al ${ }^{18}$ reported a case in which amniotic fluid cells showed a short arm deletion of chromosome 18. In situ hybridisation with a radioactive alphoid probe also illustrated less hybridisation (as measured by the number of silver grains) on the deleted chromosome 18 than on the normal 18. These authors did not report the presence of any isochromosomes in these cultures. The phenotype appears milder than the case reported by van Essen $e t a l^{10}$ with holoprosencephaly and DiGeorge anomalies. Gosden $e t a l,{ }^{19}$ on the other hand, reported a case very similar to ours and that of Fryns $e t$ $a l^{20}$ of a deletion $13 \mathrm{p} 11$ and formation of isochromosome 13. This phenomenon of deletion/isochromosome formation may thus be more prevalent than initially anticipated.

The following hypothesis can explain these observations. The initial event could have been a destabilised alphoid sequence on 18 with deletion of sequences between the telomere and the centromere. This event resulted in a deleted $18 \mathrm{p}$ with reduced centromeric alphoid sequences but a functional telomere remained. This reduction in centromeric alphoid sequences is not a new phenomenon and earlier observations have been reported. ${ }^{21}$ The formation of the isochromosome (fig 2) could have been a subsequent event because it appears to have more centromeric material than the deleted chromosome. This is similar to what was reported for chromosome 17 short arm deletion and isochromosome formation. ${ }^{22}$ This hypothesis also fits the observation of homologous sequences at telomeres and centromeres of Drosophila ${ }^{23}$ and the model of a repeat unit for kinetochore DNA. ${ }^{24}$ An alternative hypothesis is that the isochromosome originated first followed by breakage and loss of 
one of the arms and a regeneration of a telomere. While all these steps are possible, the hypothesis is less parsimonious (that is, requires more steps). The postulated fragility of the alphoid sequences on 18 might also explain other cases reported, such as the patients reported with complementary isochromosomes of both the long and short arms with the karyotype of $47, \mathrm{XY}$ or XX, $-18,+\mathrm{i}(18 \mathrm{p}),+\mathrm{i}(18 \mathrm{q})^{25} 26$ or the increased incidence of chromosome 18 whole arm translocations and isochromosome formation. ${ }^{27}$ More studies of sequences at the centromeres of specific chromosomes, ${ }^{27}$ and at the subtelomeres will help to further our knowledge of the mechanisms of these chromosome aberrations.

We are grateful to Dr Mary Nelson for providing the photographs of the fetus and to Donley Huggins and Linda Swope for technical assistance.

1 Imai HT. Centric fission in man and other mammals. In: Daniel A, ed. The cytogenetics of mammalian autosomal rearrangements. New York: Alan $\mathrm{R}$ Liss, 1988.

2 Razavi-Encha F, Raoul O, Lescs MC, Danan C. Phenotypekaryotype correlations in $\operatorname{dup}(18 \mathrm{q})$ : report of a case and review. Am $\mathcal{F}$ Med Genet 1985;21:591-5.

3 Reynolds JF, Daniel A, Kelly TA, et al. Isochromosome 12p mosaicism (Pallister mosaic aneuploidy or Pallister-Killian syndrome): report of 11 cases. Am $\mathcal{F}$ Med Genet 1987;27: 257-74.

4 Callen DF, Mulley JC, Baker EG, Sutherland GR. Determining the origin of human $\mathrm{X}$ isochromosome by use of DNA sequence polymorphisms and detection of an apparent $\mathrm{i}(\mathrm{Xq})$ with Xp sequences. Hum Genet 1987;77: apparent $236-40$.

5 Callen DF, Freemantle CJ, Ringenbergs ML, et al. The isochromosome $18 \mathrm{p}$ syndrome: confirmation of cytogenetic diagnosis in 9 cases by in situ hybridization. $\mathrm{Am}$ f Hum Genet 1990;47:493-8.

6 Lorda-Sanchez I, Binkert F, Maechler M, Schinzel A. A molecular study of $\mathrm{X}$ isochromosomes: parental origin, centromeric structure, and mechanism of formation. $\mathrm{Am}$ f Hum Genet 1991;49:1034-40.

7 Spinner NB, Eunpu DL, Austria JR, Mamunes P. Holoprosencephaly in a newborn girl with $46, \mathrm{XX}, \mathrm{i}(18 \mathrm{q})$. Am $\mathcal{F}$ Med Genet 1991;39:11-12.

8 Pettigrew AL, McCabe ERB, Elder FFB, Ledbetter DH. Isodicentric $\mathrm{X}$-chromosome in a patient with Turner syndrome - implications for localization of the X-inactivation center. Hum Genet 1991;87:498-502.

9 Abeliovich D, Dagan J, Levy A, et al. Isochromosome 18p in a mother and her child. Am $f$ Med Genet 1993;46: 392-3.

10 van Essen AJ, Schoots CJF, Vanlingen RA, et al. Isochromosome $18 \mathrm{q}$ in a girl with holoprosencephaly, $\mathrm{Di}$ -
George anomaly, and streak ovaries. Am $\mathcal{f}$ Med Genet 1993;47:85-8

11 Tharapel AT, Qumsiyeh MB, Martens PR, et al. Identification of the origin of centromeres in whole-arm translocations using fluorescent in situ hybridization with $x$ satellite DNA probes. Am f Med Genet 1991;40:117-20.

12 Schinzel A. Isochromosome formation and subsequent fission or short arm deletion and subsequent isochromosome formation. Ann Genet (Paris) 1990;33:60.

13 Cantú ES, Khan TA, Pai GS. Fluorescence in situ hybridization (FISH) of a whole-arm translocation involving chromosomes 18 and 20 with $x$-satellite DNA probes: detection of a centromeric DNA break? Am $\mathcal{F}$ Med Genet 1992;44:340-4.

14 Alitalo T, Willard HF, de la Chapelle A. Determination of the breakpoints of $1 ; 7$ translocations in myelodysplastic syndrome by in situ hybridization using chromosome-
specific alpha satellite DNA from human chromosomes 1 and 7. Cytogenet Cell Genet 1989;50:49-53.

15 Tümer Z, Berg A, Mikkelsen M. Analysis of a whole arm translocation between chromosomes 18 and 20 using fluorescence in situ hybridization: detection of a break fluorescence in situ hybridization: detection of a break in the centromeric

16 Pinkel D, Straume T, Gray J. Cytogenetic analysis using quantitative, high-sensitivity fluorescence hybridization. Proc Natl Acad Sci USA 1986;83:2934-8.

17 Pinkel D, Landegent J, Collins C, et al. Fluorescence in situ hybridization with human chromosome-specific libraries: detection of trisomy 21 and translocations of chromosome 4. Proc Natl Acad Sci USA 1988;85:9138-42. 18 Vorsanova SG, Yurov YB, Alexandrov IA, et al. 18p- syn-
drome: an unusual case and diagnosis by in situ hybridization with chromosome 18-specific alphoid DNA sequence. Hum Genet 1986;72:185-7.

19 Gosden C, Nicolaides KH, Rodeck CH. Fetal blood sampling in investigation of chromosome mosaicism in amniotic fluid cell culture. Lancet 1988;i:613-17.

20 Fryns JP, Kleczkowska A, Van Heeck K, et al. Mosaic 13 trisomy due to de novo $13 / 13$ translocation with subsequent fission. Karyotype: $46, \mathrm{XX},-13,+\mathrm{t}(13 ; 13)(\mathrm{p} 11$; sequent fission. Karyotype: $46, \mathrm{XX},-13,+\mathrm{t}(13 ; 13)(\mathrm{p} 11$;
q11)/46,XX,del(13)(p11). Ann Genet (Paris) 1989;32: q11)/46.

21 Wevrick R, Earnshaw WC, Howard-Peebles PN, Willard HF. Partial deletion of alpha satellite DNA associated with reduced amounts of centromere protein CENP-B in a mitotically stable human chromosome rearrangement. Mol Cell Biol 1990;10:6374-80.

22 Andersen LB, Tommerup N, Koch J. Formation of a minichromosome by excision of the proximal region of $17 q$ in a patient with von Recklinghausen neurofibromatosis. Cytogenet Cell Genet 1990;53:206-10.

23 Young BS, Pession A, Traverse KL, et al. Telomere regions in Drosophila share complex DNA sequences with pericentric heterochromatin. Cell 1983;34:85-94.

24 Zinkowski RP, Meyne J, Brinkley BR. The centromere kinetochore complex: a repeat subunit structure. $\mathcal{F}$ Cell Biol 1991;113:1091-110.

25 Muller H, Buhler EM, Signer E, et al. Trisomy 18 syndrome caused by translocation or isochromosome formation: a cause report with bibliography. 7 Med Genet 1972;9:462-5.

26 Larson LM, Wasdahl WA, Saumer JH, et al. Trisomy 18 syndrome with an unusual karyotype: possible double isochromosome. f Med Genet 1978;15:73-6.

27 Willard HF. Centromeres of mammalian chromosomes. Trends Genet 1990;6:410-16. 